\title{
UM COLÉGIO PARA OS ÍNDIOS DE URUBÁ: O PROJETO DO CÔNSUL DE PORTUGAL PARA A PROVÍNCIA DE PERNAMBUCO
}

\author{
Irma Rizzini ${ }^{1}$ \\ Universidade Federal do Rio de Janeiro \\ irma.rizzini@gmail.com
}

\section{RESUMO:}

O artigo tem por objetivo a análise das concepções e propostas do cônsul de Portugal no Recife, Domingos Maria Gonçalves, a respeito da educação dos índios aldeados pelo governo da Província de Pernambuco. Ao assumir o consulado do Recife, Gonçalves visitou a Aldeia de Urubá (Cimbres) e elaborou um projeto de educação agrícola e artesanal dirigido às crianças e aos índios adultos do aldeamento. $\mathrm{O}$ artigo se debruça sobre a obra do autor, Collegio dos Indios de Urubá de Agricultura, e Artes Industriaes, publicada em 1874, e analisa as disputas em torno das aldeias e a recepção ao projeto do cônsul, amparando-se nesta fonte, nos relatórios da presidência da província e na historiografia. A despeito dos esforços para erguer o colégio indígena, Gonçalves encontrou forte oposição de instâncias do governo imperial e provincial. Pela própria situação dos índios na região - aldeados ou misturados à população - a educação dos índios não era vista como uma questão que merecesse tratamento diferenciado. Os aldeamentos do nordeste brasileiro foram alvo de política sistemática de extinção ao final do Império, com efeitos drásticos sobre a identidade étnica dos povos remanescentes, gerando, todavia, lutas de resistência dos grupos por sua sobrevivência material e cultural.

Palavras-chave: Aldeamentos indígenas. Colégios indígenas. Ensino profissional. Domingos Maria Gonçalves. Província de Pernambuco.

\section{A SCHOOL FOR THE URUBA INDIANS: A PROJECT BY THE PORTUGUESE CONSUL AT THE PROVINCE OF PERNAMBUCO}

\begin{abstract}
:
This article aims at analyzing concepts and proposals of the Portuguese consul at Recife, Domingos Maria Gonçalves, regarding the education of natives settled in villages by the Pernambuco provincial government. When he assumed his post at the Recife consulate, Gonçalves visited the Urubá Village (Cimbres) and designed an education project in crafts and agriculture for children and adults of the Indian village. This article surveys Gonçalves' work entitled Collegio dos Indios de Urubá de Agricultura, e Artes Industriaes (The Uruba Indian School of Agriculture and Industrial Arts), published in 1874, and analyzes disputes concerning the villages and the acceptance of the consul's project, using his book as source, along with provincial government reports and historiography. Despite his efforts towards establishing the Indian school, Gonçalves met with strong opposition from imperial and provincial government jurisdictions. Due to the Indians' own status in that region - who were either in villages or among the rest of the population - Indian education was not perceived as a subject that deserved differentiated treatment. Indian villages in Northeastern Brazil were subject to systematic extinction policies at the end of the Empire, with drastic effects on the ethnic identity of the remaining peoples, generating, however, resistance movements by those groups for their material and cultural survival. Keywords: Indian villages. Indian schools. Occupational training. Domingos Maria Gonçalves. Pernambuco Province.
\end{abstract}




\section{Introdução}

Poucos meses antes da aprovação da Lei do Ventre Livre ${ }^{2}$ desembarcava nestas terras o lisbonense Domingos Maria Gonçalves. O desejo de conhecer as populações "primitivas" e os seus costumes motivou Domingos Gonçalves (1848-?) a viajar para o Brasil, após um convite do Duque d'Ávila e Bolama para assumir interinamente o consulado de primeira classe de Portugal em Pernambuco. O cônsul chegou ao Brasil em junho de 1871, em meio a um intenso debate sobre a formação do trabalhador livre, abarcando temas como a educação dos libertos, dos índios e dos desvalidos em geral. Ao assumir o consulado do Recife, Gonçalves visitou a Aldeia de Urubá ${ }^{3}$, administrada pelo governo provincial. Lá encontrou inspiração para elaborar um projeto de educação dos índios, que o levou a enfrentar os meandros da política imperial. Tendo se dedicado à leitura da literatura brasileira e estrangeira que abordava a temática indigenista, o cônsul se lançou ao esforço de observação e intervenção de modo a fundamentar o "plano de instrucção popular" (GONÇALVES, 1874, p. 3), denominado, posteriormente, "plano de civilisação para os indios mansos" (GONÇALVES, 1880, p. 10).

Preocupado em dar publicidade aos seus projetos educacionais, Gonçalves deixou três obras, publicadas nas cidades do Recife e Rio de Janeiro, contendo detalhados relatos da trajetória percorrida nas frustradas tentativas para viabilizar suas ideias: Collegio dos Indios de Urubá de Agricultura, e Artes Industriaes (1874), A instrucção agricola e o trabalho livre (1880), Exposição ao Poder Legislativo (1882). Na brochura de quinze páginas, publicada no Recife, em 1874, o autor descreve o plano de instrução elementar e agrícola, por ele elaborado para ser aplicado aos índios da "aldeia de Urubá" (GONÇALVES, 1874, p. 3). A brochura é reproduzida no livro de 1880, na seção "Historia das minhas tentativas para o estabelecimento d'escolas agrícolas", sob a justificativa da edição de 1874 ter se esgotado (GONÇALVES, 1880, p. 9-22). As obras da década de 1880 contêm o relato de suas lutas para implementar um projeto de educação agrícola dos filhos das escravas, nascidos livres após a lei de 1871. As fontes do presente estudo estão centradas na brochura de quinze páginas, publicada no Recife, no ano de 1874, e nos relatórios da presidência de Pernambuco, focalizando as disputas em torno das aldeias e a recepção ao projeto do cônsul.

A análise das concepções e propostas de Domingos Maria Gonçalves a respeito da educação dos índios aldeados pressupõe a compreensão da política indigenista do país, e particularmente, do governo pernambucano, como também das representações que circulavam entre os grupos intelectuais e as autoridades públicas sobre as possibilidades de civilização dos índios. Gonçalves contesta o que considerou ideias preconcebidas e equivocadas da literatura sobre os índios brasileiros, buscando demonstrar que os aldeados de Urubá se encontravam aptos ao trabalho regular. As propostas do cônsul, como outras desenvolvidas no período, obedeciam aos recortes étnico, econômico e social, expressos no pressuposto da participação de populações não brancas e desvalidas na vida social e econômica das províncias pela via do trabalho, como operários e trabalhadores rurais, de forma disciplinada, no tempo e no espaço.

Em Portugal, Gonçalves participou de associações de instrução popular e publicou artigos sobre o tema em periódicos literários. A sua formação deu-se nas seguintes instituições: Curso Superior de Letras, Instituto Industrial, Escola do Comércio e Liceu de Lisboa. Continuando a consulta ao Diccionario bibliographico dos escriptores portuguezes (SILVA, 1858-1923, v. IX, p.146), recomendada pelo autor aos seus leitores, verifica-se que o lisbonense abriu várias frentes de atuação profissional em Portugal. Além da área educacional, exerceu por alguns anos o cargo de "condutor de Engenharia Civil" e 
desempenhou várias comissões, como a que colheu apontamentos para a história da indústria portuguesa (1865 e 1866), e selecionou objetos de arte antiga nos distritos do Porto e Braga para serem enviados à Exposição Universal de Paris, em 1867. No ano de 1870, foi nomeado Cônsul de Portugal em Nantes, após se submeter ao mesmo concurso público que aprovou José Maria Eça de Queirós. ${ }^{4}$

A afirmação do autor de que a lei de 28 de setembro de 1871 chamou sua atenção para "a questão econômica do trabalho livre", dando mais ânimo ao "desejo de conhecer os habitantes primitivos do Brasil", nos permite entender que Gonçalves estendia aos escravos a condição de primitivos, visto que, as duas categorias se encontravam alijadas das luzes da instrução (GONÇALVES, 1880, p. 9). O autor se dedicará, em meados da década de 1870, à articulação de um programa de educação dos "ingênuos" e "menores pobres" (Op. cit., p. 24 e 54) na cidade de Campos, enfrentando resistências de fazendeiros locais, de instâncias do Governo Central e do Governo da Província do Rio de Janeiro. A trajetória de mais de uma década em prol da educação das camadas consideradas social e etnicamente inferiores é contada pelo autor nas obras da década de 1880. Gonçalves acreditava na importância em dar "publicidade" aos seus projetos como meio de angariar apoio aos mesmos, nos setores públicos e privados. Muitos artigos na imprensa da Corte e da cidade de Campos retrataram as suas tentativas de estabelecer asilos agrícolas para os ingênuos. Ele chegou a ser proprietário de duas folhas diárias, Commercio de Campos e Jornal da Província, e da folha semanal, d'O Agricultor Progressista, veículos de suas ideias a respeito da questão do trabalho livre e da instrução agrícola. ${ }^{6}$

O autor lembra que publicou o "plano de civilisação para os indios mansos' ao mesmo que tempo que o seu "ilustrado amigo, corajoso viajante e sabio brazileiro o $\mathrm{Sr}$. Dr. Couto de Magalhães" publicou o "precioso livro", O Selvagem, onde "procura chamar a atenção pública para o seu sistema de civilização d'índios bravios" (GONÇALVES, 1874 , p. 10). A obra de Couto de Magalhães, O Selvagem, obteve grande sucesso no Brasil e na Europa à época de sua publicação (1875), sendo citada por autores nacionais e estrangeiros. Domingos Gonçalves é um deles. Crítico austero de várias obras sobre os índios brasileiros, o cônsul português se mostra simpático à obra de Magalhães por confirmar a sua crença na capacidade de trabalho da população indígena. Magalhães não apenas buscou inspiração para seus escritos na literatura e na observação, tendo empreendido pessoalmente experiências de educação junto aos chamados "índios selvagens". Em 1870, com o apoio do Governo Imperial, fundou o Colégio Isabel, cujo nome homenageava a princesa herdeira do trono. A instituição destinava-se à educação para o trabalho de meninos e meninas oriundos das "tribos selvagens" do Araguaia, na Província de Goiás. O internato indígena foi dirigido pelo então Brigadeiro José Vieira Couto de Magalhães nos seus primeiros sete anos de existência (CAUME, 1997).

As propostas educacionais dirigidas às crianças indígenas no período inseriam-se no debate da falta de braços para a colonização dos vastos sertões do país. O ensino profissional dirigido à infância desvalida, aos ingênuos e aos filhos dos índios não se orientava apenas pela perspectiva técnica, mas também moral e cultural: ao ensino das primeiras letras, de técnicas agrícolas, e dos ofícios mecânicos, associava-se a "inoculação do amor ao trabalho" e dos valores cristãos. Torna-se premente manter os ex-escravos nos locais de trabalho, principalmente nas áreas rurais, onde se previa um grande êxodo com o rompimento dos laços que os prendiam ao trabalho. No caso dos índios, a discussão assume matizes bastante específicos, pelas concepções que circulavam entre autoridades e intelectuais a respeito da possibilidade de civilizá-los, tornando-os trabalhadores "úteis à nação". Dentre os debates apaixonados sobre as vantagens da imigração ou do aproveitamento do elemento nacional, algumas vozes defenderam a inserção dos índios nas 
frentes de trabalho, tanto do setor público quanto do privado. Buscava-se, por esta via, resolver a carência populacional do país em termos de mão-de-obra disciplinada para o trabalho regular, já que, conforme apregoava Couto de Magalhães, milhares de indivíduos viviam à margem da civilização, em "hordas selvagens" arredias ao contato com os chamados civilizados e avessas aos benefícios da "vida civilizada". Era toda uma riqueza não aproveitada, que o autor estimava em "um milhão de braços aclimados e os únicos que se prestam às indústrias - extrativas e pastoris" (MAGALHÃES, 1975, p. 14).

A década de 1870 foi pródiga na produção de representações ${ }^{7}$ sobre a educação para o trabalho da população livre e liberta do país. O tema da educação permeou os debates dos Congressos Agrícolas de Recife e do Rio de Janeiro, realizados em 1878. Duas posições polarizaram as discussões referidas a esta temática: no Norte, a educação foi percebida como preparação da chamada mão-de-obra nacional para o trabalho, e no Sul, a educação dos ingênuos e desvalidos como mão-de-obra seria um estágio para a introdução de trabalhadores estrangeiros no Brasil (FONSECA, 2002). A respeito da relação entre colonização e clima, algumas regiões foram eleitas como capazes de receber colonos europeus, enquanto outras tiveram como solução proposta o aproveitamento da população local: homens livres pobres e não proprietários, os libertos, os nascidos livres após a lei de 1871 e os índios. Os projetos de Gonçalves a educação de índios, ingênuos e desvalidos catalisam estes debates, visando à modernização da agricultura a partir dos estratos considerados os mais baixos da sociedade brasileira da época.

\section{Combates pela educação dos “índios mansos” de Urubá}

As batalhas enfrentadas por Domingos Gonçalves no esforço de concretizar seus projetos não foram poucas: o combate às representações que negavam aos índios toda possibilidade de educação e os embates políticos com representantes do Estado Imperial. Suas armas eram os impressos: a imprensa periódica e as brochuras editadas. Todavia, não descuidou do contato pessoal com as principais autoridades governamentais do Império.

O "plano" de Domingos Gonçalves dirigia-se aos "índios mansos", aldeados pelo governo pernambucano. Os denominados "índios mansos" ou "domesticados", em contraposição aos "selvagens", eram aqueles que viviam em contato com os chamados civilizados, geralmente nos aldeamentos oficiais ou nos povoados. ${ }^{8}$ A Aldeia de Urubá localizava-se no agreste pernambucano, entre a Vila de Cimbres e a de Pesqueira, cujas terras Gonçalves considerou abençoadas por Deus, devido ao clima e à fertilidade. ${ }^{9}$ Habitavam-na 1.500 indivíduos de "origem índia", sendo que "poucos conservam a pureza primitiva do sangue" devido aos "cruzamentos com o elemento negro", mestiçagem percebida como negativa pelo autor segundo os modelos desenvolvidos pelos teóricos raciais da época (GONÇALVES, 1874, p. 4). Autores como Kidd, Le Bon, Taine e Gobineau, calcados nas teses poligenistas da origem diversa das raças, acreditavam que, em termos de degenerescência, pior do que as taxadas de raças puras inferiores eram as mestiças (SCHWARCZ, 1995, p. 177).

$\mathrm{Na}$ segunda metade do século XIX, as teses monogenistas e poligenistas foram alvos de debates por intelectuais europeus e brasileiros, tendo como foco a miscigenada população brasileira. Lilia Schwarcz (1995a, 1995b) discute a incorporação destas teorias pela intelectualidade brasileira, alocada nos poucos centros de produção de conhecimento do país, como os museus etnográficos, os institutos históricos e as faculdades de medicina e direito, questionando a ideia de que houve uma importação direta das teorias, sem adaptações e reconstrução de conceitos. As contradições estavam presentes nos autores que 
adotavam as teses poligenistas e que tinham que lidar com a perspectiva pessimista de um país miscigenado. ${ }^{10}$ Gonçalves, que acompanhava estas discussões, não escapou às contradições quando se debruçou sobre um projeto de educação de índios mestiços. A mestiçagem entre índios e negros não era bem vista pelo autor, que ao mesmo tempo, precisava provar que essa condição racial não condenaria o seu projeto pedagógico. A saída foi demonstrar pela observação, que os índios da aldeia eram bons trabalhadores e não se entregavam às desordens.

Estudos e observações deveriam orientar o projeto educacional, conforme ressaltou Gonçalves $(1874$, p. 8). O autor condena a forma como os índios vinham sendo estudados por escritores nacionais e estrangeiros, os quais não se davam ao trabalho de observação, resultando na divulgação de visões equivocadas sobre os índios do Brasil como "verdade axiomática" ( p. 7). Gonçalves analisa parte desta literatura, discordando das posições que podiam contrariar os pressupostos do seu projeto, ou seja, a visão de que o índio resistia ao trabalho. Para ele, o maior problema dos escritores era de método: escreviam sobre o que não observaram, e mesmo que tivessem observado, não comparavam o que viam com a realidade dos habitantes rurais que, em muitos aspectos, compartilhavam com os índios, condições de vida aproximadas. ${ }^{11}$ Ao seu ver, "a raça branca e a raça preta" não tinham o mesmo valor do que a indígena em relação ao trabalho, e nem tampouco, eram seus representantes "tão destros, nem espirituosos quanto os índios". A cidadania era o grande diferencial entre os índios e os habitantes rurais, na visão do autor. Propriedade, capital, educação, religião e ordem seriam os bens advindos da condição de cidadão:

Os habitantes ruraes não tutelados tem a seu favor o gozarem dos foros de cidadãos - no civel e comercial, o que é vetado aos indios: podem ser proprietarios do terreno que cultivam; ter credito e obter capitais; têm escolas, padres, policia, etc. (GONÇALVES, 1878, p. 7).

A qualificação de "selvagens" aplicada aos índios é combatida pelo autor, sob o argumento de que "se os índios vivem tão "selvajadamente", os outros pequenos habitantes rurais são também "selvagens"” (Idem). Baseado no conhecimento obtido sobre a Aldeia de Urubá, Gonçalves afirma que os índios eram superiores, nos aspectos mais inesperados, aos ditos "civilizados": na aldeia que visitou, trabalhava-se muito na lavoura, com "amor e obediência" e sem desordens. O modo de vida, calcado no duro trabalho agrícola, contrariava as teses da resistência ao trabalho defendida pelos autores citados por Gonçalves. $^{12}$

Os indios trabalham tanto ou mais do que os outros habitantes pobres d'estas paragens. [...] Plantam milho, feijão, mandioca e algum algodão tão bem como os outros; não há nenhum ladrão de cavalo; raramente há na aldeia um crime de ferimentos e outros atentados contra as pessoas e a propriedade não obstante a ausencia de autoridade de policia, sendo esta feita pelos proprios indios; são acusados de se entregar muito ao uso da aguardente, o que não é verdade, tendo em vista o numero de embriagados em relação á população. (GONÇALVES, 1878, p.5).

No âmbito da política indigenista, Gonçalves conta que obteve o apoio do $1^{\mathrm{o}}$ Diretor Geral dos Índios da Província, Barão de Buique, e do $2^{\circ}$ Diretor parcial da Aldeia de Urubá, Tenente-Coronel Severiano Monteiro Leite, para a criação do colégio. Não menciona o apoio de setores da Igreja, mas o vigário local assinou como testemunha o contrato estabelecido entre Gonçalves e o Barão de Buique, no qual se prescrevia o ensino religioso aos índios. $\mathrm{O}$ autor não justifica a criação de uma instituição de instrução e 
formação profissional para uma comunidade que, segundo suas próprias observações, funcionava de forma tão harmoniosa. Nesse ponto, ele se contradiz, na ânsia de demonstrar as vantagens, econômicas e políticas, da criação do colégio indígena: “[...] uma povoação que hoje é inutil, e amanhã talvez perigosa, será transformada em um povoado trabalhador e policiado; terrenos que estão no estado de manin hoss, desbravados e cultivados (GONÇALVES, 1878, p.5).

Uma rápida observação, feita em uma publicação posterior, demonstra que sua visão sobre os índios aldeados não era das mais positivas. Comentando os dados do Censo Imperial de 1872, o cônsul relata que o Brasil possuía 388.958 "índios aldeados, viciados, estragados pela falsa educação que se lhes deu, eles que por lei não tem direitos civis nem políticos" (GONÇALVES, 1880, p. 28). ${ }^{13}$ Esta pode ter sido uma opinião consolidada após de anos de residência no Brasil, mas é provável que Gonçalves pretendesse fazer em Urubá um ensaio das ideias que defendia sobre a educação dos "habitantes primitivos" do Brasil. A intenção era propor um "novo gênero de indústria e caridade", criando-se muitos estabelecimentos sem ônus para a nação, onde os "empresários" seriam recompensados, enriquecendo-se e enriquecendo aqueles que os cercavam. O sistema evitaria o pobre pela instrução e amor ao trabalho (p. 12). A associação entre indústria e assistência à infância não era nova na Europa pós-revolução industrial. Asilos para órfãos e filhos de trabalhadores foram criados no início do século XIX, principalmente na Inglaterra e na França, para atender às necessidades de braços para as fábricas. Crianças, a partir dos oito anos de idade, não só eram treinadas e domesticadas na disciplina fabril, mas a sua força de trabalho era explorada de forma imediata (ALVIM, 1985, p. 387-400). Gonçalves, no afã de conquistar parceiros, propõe uma modalidade de tutela a uma categoria considerada incapaz de gerir a própria vida, formada por índios, escravos, ingênuos e os meninos desvalidos das cidades, tutela a ser exercida pelo cerceamento produzido pelo trabalho compulsório e pelo viver em espaços controlados pelos empregadores.

A proposta resultou no contrato mencionado, assinado entre o Barão de Buique, na qualidade de Diretor Geral dos Índios da Província, e o Dr. Domingos Maria Gonçalves, no cartório da vila de Pesquisa, termo da comarca de Cimbres, em 12 de março de $1874 .{ }^{14}$ Nele, são estabelecidas as obrigações dos responsáveis pela instalação do colégio: o contratante Domingos Maria Gonçalves (artigo $1^{\circ}$ ), a Diretoria Geral dos Índios da Província de Pernambuco (artigo $2^{\circ}$ ) e o Estado e o contratante Domingos Maria Gonçalves juntos (do artigo $3^{\circ}$ ao $6^{\circ}$ ). Os principais interessados, os índios, são apenas citados como alvos do processo educacional, os sujeitos escolares (FARIA FILHO et al, 2004). Assinaram como testemunhas, o Tenente-Coronel Severiano Monteiro Leite e o Vigário Domingo Leopoldino da Costa Espinosa.

Gonçalves se obrigava "a ensinar simultaneamente a cem índios maiores de 10 anos a ler, escrever, contar, doutrina cristã, desenho geométrico e princípios de arquitetônico", sob o regime de internato, ao longo de quatro anos (GONÇALVES, 1874, p. 9). Aos meninos seriam ensinados ofícios mecânicos úteis à localidade, tais como, "ferreiro, carpina, sapateiro, alfaiate, etc, produção e criação de gados, princípios de veterinária e agricultura prática com princípios de teórica" (p. 9). Haveria também uma escola noturna, não só para os índios adultos, mas para outras pessoas estudarem gratuitamente. Seria instalada uma "escola prática de agricultura nos terrenos da aldeia, onde se cultivarão pelos processos mais econômicos, não só as plantas indígenas de maior valor, mas muitas das exóticas de reconhecida vantagem para a província" (GONÇALVES, 1878, p.9). A educação agrícola incorporaria os conhecimentos indígenas sobre a flora local, de valor comercial. 
Ao Diretor de Índios cabia garantir a terra para o ensino da agricultura e a presença dos índios no internato, na escola prática de agricultura e na escola noturna. Não é mencionada a obrigatoriedade do ensino primário, agrícola ou artesanal, porém, está claro que o projeto seria imposto aos índios. Não há qualquer referência nos escritos de Gonçalves sobre o que pensavam os índios a respeito do plano que o cônsul e o diretor de índios pretendiam implementar em seu "benefício". Como seres "primitivos", excluídos dos benefícios da cidadania, possivelmente os índios eram vistos como incapazes de compreender o bem que as luzes da instrução e da civilização poderiam trazer para as suas vidas.

O governo da província cuidaria da inspeção sobre a execução do contrato, velando pelo "bem-estar moral e physico dos educandos" (artigo $4^{\circ}$ ) e "a conceder todos os foros de cidadão brazileiro aos alunnos que tenham completado com vantagem o quadrienio escolar, logo que estes tenham chegado á idade de vinte e um annos" (artigo $6^{\circ}$ ). No decorrer dos anos, a educação proporcionada pelo colégio acarretaria profundas mudanças no status político e na identidade étnica da aldeia, produzindo através do processo educacional e da via jurídica, cidadãos brasileiros. Ressalta-se que projeto envolvia não somente as crianças, mas as famílias, cujos homens aptos para o trabalho deveriam estar disponíveis ao colégio, afetando a vida de todos. Tratava-se de uma proposta bastante ambiciosa, que abrangia a educação de crianças e adultos, dentro de uma lógica de trabalho que se impunha no e pelo mundo ocidental.

A meta era tornar o colégio autossuficiente com outras produções, como o trigo, a cevada, a vinha, o cacau, o tabaco, etc. O governo não teria despesa alguma, mas cederia por vinte anos um sítio na aldeia, à escolha do reformador. A instituição deveria contar com a mão-de-obra indígena para o serviço de campo, calculada em 300 índios aptos para esta atividade. Todos os agricultores iriam freqüentar, uma vez por semana, a escola prática de agricultura e, diariamente, a escola noturna. O ensino das artes industriais seria ministrado nas oficinas, com a introdução do "princípio econômico da divisão do trabalho". Em vinte anos, esperava ter de 500 a 600 "operários instruídos". Em proposta à Assembléia Provincial, Gonçalves pretendeu que os benefícios dessa educação fossem estendidos a vinte órfãos pobres da comarca, mediante o empréstimo de doze contos de réis dos cofres provinciais e a concessão de um terreno para edificar o colégio (NÇALVES, 1874, p. 11).

Aliada às transformações na identidade cultural do grupo, a perda da condição de índio pela incorporação legal à condição de cidadão brasileiro aceleraria o processo de perda do direito ao uso da terra. Em 1850, houve uma grande transformação com relação à posse da terra no território brasileiro. A chamada Lei das Terras (Lei $\mathrm{n}^{\circ} 601$ de 18/09/1850) determinou que todas as terras deveriam ser adquiridas por compra e somente aos índios selvagens foi prevista a reserva de áreas para o seu assentamento em aldeamentos. Onde não mais existissem "hordas de índios selvagens", as terras deveriam ser vendidas. Aldeias com habitantes considerados já civilizados sofreram uma campanha sistemática de extinção, tendo seus territórios incorporados aos próprios nacionais, principalmente nas províncias mais povoadas, como as da região que hoje corresponde ao Nordeste (MOREIRA NETO, 1971, p. 373). ${ }^{15}$

Estabelecido o contrato com a Diretoria de Índios, iniciou-se a longa jornada de Gonçalves em prol da criação de estabelecimentos de educação agrícola no país, e com isso, uma complicada tramitação de seus projetos pela burocracia dos governos provincial e Imperial. Enviado o contrato à Presidência da Província de Pernambuco, para obtenção da aprovação do Ministro da Agricultura, nada foi feito, "segundo o costume" (GONÇALVES, 1880, p. 20). Gonçalves, munido de uma carta particular de apresentação 
ao Ministro da Agricultura, Conselheiro Costa Pereira, foi à Corte tratar pessoalmente da aprovação do contrato. Aqui começa a sua peregrinação pelos meandros da política imperial. Afirma ter sido bem recebido por Suas Majestades Imperiais, pelo Ministro da Agricultura e pelo Ministro do Império Conselheiro João Alfredo. No entanto, o Ministro da Agricultura "cobriu o contrato com um ofício", de 27/07/1874, desaprovando a sua execução por considerá-lo incompatível com alguns pontos da Constituição do Império. Gonçalves, demonstrando irritação, questiona se o Ministro "sabe direito público brasileiro" (Idem). ${ }^{16} \mathrm{O}$ fato é que daí em diante só enfrentou resistência dos poderes públicos, embora angariasse a simpatia da imprensa carioca. Outro argumento contra a criação do estabelecimento partiu, na visão de Gonçalves, de "ideias pequeninas e egoístas do Diretor de Agricultura de então", que a despeito de aprovar o projeto, por resolver "completamente o problema de civilização d'índios e da colonização nacional", não recomendava que tais iniciativas viessem de outrem, senão do Estado (GONÇALVES, 1880, p. 21). Em 1874, o governo imperial fundava o Asilo de Meninos Desvalidos, para a formação profissional das crianças desamparadas do município da Corte (SOUZA, 2008). Em Valença, interior da província do Rio de Janeiro, dirigentes imperiais mantinham, com subsídio público, o Asilo Isabel, voltado para o ensino agrícola de meninos pobres e ingênuos (SCHUELER, 2000). Com isso, conclui um desolado Gonçalves (1880, p. 21):

Desta luta resultou, que nem o Estado, nem eu fizéssemos coisa alguma a tal respeito, e os verdadeiros brasileiros, os índios, ainda, na phrase do honrado Dr. Couto de Magalhães "erram selvagens pelo meio dos nossos sertões, á espera de que lhes vamos levar a civilisação e o trabalho!!"

Gonçalves não recuou no seu propósito de promover a instrução agrícola no país, adaptando-o para o atendimento aos desvalidos e ingênuos. Preparou um bem elaborado projeto para criação de "estabelecimentos zootécnicos" (o primeiro seria implantado em Campos e os outros, em cinco províncias), para criação, reprodução e engorda da raça suína, "a exemplo do que é feito em outros países" (Hungria, Sérvia, Hamburgo, Portugal e Estados Unidos), resultando em total fracasso, pois não conseguiu o apoio esperado dos setores públicos e privados (GONÇALVES, 1880, 1882). As suas tentativas de estabelecer no Município de Campos "uma escola agrícola teórica e prática" para 200 "menores" (Lei n. 2455 de 22/12/1879), com o mesmo plano pedagógico do Colégio de Urubá, foram infrutíferas. Na década seguinte, assentada a poeira levantada pelo cônsul, o autor da obra mais completa do século XIX sobre o ensino técnico no Brasil limita-se a informar, sem citar o nome de Gonçalves, que a escola agrícola de Campos e as Estações Agronômicas, "criadas em mais recente data", não tiveram execução "por falta de meios" (SOUZA FILHO, 1887, p. 98). Em outro trabalho, Gonçalves (1880b, p. VI) se queixa dos nove anos que aqui perdeu e anuncia a sua partida desta terra, para talvez, não mais voltar.

\section{Considerações finais: os empecilhos à criação do colégio de índios}

Afora os ressentimentos do cônsul a respeito do que chamou de "picuinhas" promovidas por "invejosozinhos" (GONÇALVES, 1880b, p. 47), supostamente incomodados com o fato de um cidadão português conseguir publicidade para criar uma instituição que deveria resultar da iniciativa do Estado, outros motivos parecem ter impedido o avanço da proposta. A educação foi uma das estratégias pensadas para a civilização dos índios e sua incorporação à sociedade nacional como trabalhadores. $\mathrm{Na}$ prática, pouco foi feito neste sentido no Oitocentos, ao menos em termos da criação de 
internatos indígenas. Os aldeamentos sofreram uma política de extinção e de transformação das aldeias em povoados, no século XIX. Os índios aldeados foram gradativamente incorporados à população livre empobrecida, dentro da terminologia que designava os moradores do interior (caboclos na Amazônia e sertanejos no Nordeste, por exemplo).

No caso de Pernambuco, o governo provincial extinguiu nos anos de 1874 e 1875 cinco dos oito aldeamentos existentes. A medida ocorreu por indicação de uma comissão criada com a finalidade de emitir parecer sobre as aldeias que deveriam ser extintas, em cumprimento ao aviso do Ministério da Agricultura de 27/03/1872. A aldeia de Cimbres (Urubá), considerada a única que apresentava boas condições com relação à população e à cultura agrícola, não foi extinta nessa leva. O governo determinou que parte das terras das aldeias extintas fosse repartida em lotes para as famílias dos índios "que se mostrarem amigas do trabalho e capazes de atividade agrícola, vendendo-se em hasta pública o restante de tais terrenos" (LUCENA, 1875, p. 147). Dois anos depois, é relatado que os próprios índios vinham abandonando as aldeias restantes, migrando em sua maior parte, para a Província da Bahia (CUNHA, 1877, p. 79). Não é apresentada qualquer explicação para este fato, mas a política governamental de extinção das aldeias e a violência empregada na expropriação de suas terras são hipóteses plausíveis para a compreensão do fenômeno. ${ }^{17}$

O governo pernambucano posicionou-se contra a manutenção do "serviço de catequese e civilização dos índios", alegando que a população que habitava as aldeias achava-se "em condições de dispensar a vida dos aldeamentos e ser sujeita ao regime comum" (LUCENA, 1875, p. 147). O engenheiro encarregado da medição das terras públicas da Província sustentou tal posição, "pela maneira por que estão seus habitantes confundidos com a população, e assim esquecidos seus usos primitivos" (Idem). Além dos motivos relacionados à raça e à cultura, o engenheiro apontou ao governo as questões dos conflitos de terras e das espoliações que os índios sofriam dos especuladores que os perseguiam. Ao índio deveria ser privada a "faculdade de alienar" a terra, por precaução contra a ambição dos especuladores e como meio de "prendê-lo ao solo" (LUCENA, 1875 , p. 146-147). ${ }^{18}$ Ao mesmo tempo em que as autoridades públicas defendiam a integração dos índios ao "regime comum", sustentavam a manutenção de uma espécie de tutela destinada a mantê-los no local, sob uma nova organização social que afetaria a identidade étnica e dissiparia o poder do grupo de lutar e negociar por direitos. Em 1879, o Aldeamento de Cimbres foi extinto.

Não se vislumbrava o porquê de investir, através de projetos especiais, na educação de uma população já incorporada aos hábitos de vida da população brasileira. Para os seus filhos havia umas poucas escolas públicas e esparsas experiências de colônias agrícolas, as quais acabavam por receber, em maior número, os indesejados das cidades. ${ }^{19}$ Pela própria situação dos índios na região - aldeados ou misturados à população ${ }^{20}$ - a educação dos índios não era vista como uma questão que merecesse tratamento específico, em termos de investimentos em instituições destinadas ao ensino profissional de crianças indígenas. A política educacional prevista para os aldeamentos do Império se restringia à instalação de escolas de primeiras letras, administradas, em geral, por missionários. Alguns internatos de formação para o trabalho manual funcionavam nas cidades, como as Casas de Educandos Artífices, podendo receber crianças indígenas encaminhadas por Diretores de Índios. Todavia, a maior parte dos educandos provinha das cidades. Não há nenhum indício da existência de escola primária no Aldeamento de Cimbres. Outro aldeamento de Pernambuco, situado em região de terras férteis, tampouco tinha escola: na Aldeia da Escada, os índios não sabiam ler nem escrever, o que não os impediu de fazer petições e 
abaixo-assinados dirigidos às autoridades da Província, recorrendo à redação de terceiros (SILVA, 1995). Ressalto que a historiografia tem revisto a concepção de que o aldeamento resultou apenas de uma imposição da política indigenista colonial e imperial, tendo atuado também como palco de lutas e negociações pela sobrevivência material e cultural por parte de grupos indígenas (ALMEIDA, 2003).

Segundo Marta Amoroso (1998), as escolas primárias instaladas nos aldeamentos do século XIX enfrentavam dificuldades devido à resistência dos índios mais velhos. Missionários viam a permanência das crianças em poder dos pais como um fator prejudicial a uma "educação completa" dos pequenos. Pode-se pressupor que tais empecilhos tenham levado a uma revisão das formas escolares. Assim, na primeira década republicana, internatos indígenas surgiram sob a administração de missionários e missionárias, instalados em reservas mantidas pelos governos locais. Capuchinhos da Ordem da Lombardia fundaram, nos núcleos indígenas instalados ao norte do país (Maranhão, Pará, Piauí e Ceará), internatos para a educação de meninos e meninas (GOMES, 2002; RIZZINI e SCHUELER, 2009). Interessante observar como no regime republicano, que oficializou a separação entre o Estado e a Igreja em $1890^{21}$, governos locais fundam políticas indigenistas amparadas nas ordens religiosas. Mas, essa é outra história...

A despeito das políticas indigenistas do Império e da República, voltadas para a assimilação dos grupos indígenas à sociedade nacional, nas últimas décadas do século XX o país assistiu ao ressurgimento de etnias tidas como extintas no Nordeste, a partir da lutas políticas dos remanescentes dos aldeamentos do século XIX. ${ }^{22}$ A etnia Xukuru, com significativa concentração de indivíduos no Aldeamento de Cimbres, sobreviveu a um longo processo de espoliação de suas terras e de seus referenciais culturais. Remanescentes Xukuru permanecem na Serra do Ororubá como pequenos agricultores e o antigo aldeamento se manteve como um lugar de significância cultural para o grupo: a atual Aldeia de Cimbres concentra suas manifestações mítico-religiosas de caráter híbrido, onde seus costumes e cantigas em dialeto se misturam à tradição cristã e à língua portuguesa (GASPAR, 2009; SILVA, 2007). ${ }^{23}$ Como o projeto de Gonçalves não se realizou, surge a indagação: caso o Colégio de Índios, com sua proposta pedagógica, tivesse logrado sucesso, que efeitos se fariam sentir sobre a identidade cultural do grupo?

\section{Referências}

ALMEIDA, Maria Regina Celestino. Metamorfoses Indígenas: identidades e cultura nas aldeias coloniais do Rio de Janeiro. Rio de Janeiro: Arquivo Nacional, 2003.

ALVIM, Maria Rosilene Barbosa. Constituição da família e trabalho industrial: um estudo sobre trabalhadores têxteis numa fábrica com vila operária. Tese (Doutorado em Antropologia). Rio de Janeiro: Programa de pós-graduação em Antropologia Social, Museu Nacional/UFRJ, 1985.

AMOROSO, Marta Rosa. Mudança de hábito: catequese e educação para índios nos aldeamentos capuchinhos. Rev. Bras. de Ciências Sociais, vol. 13, no. 37, p. 101-114, 1998. Disponível em: 〈http://www.scielo.br>. Acesso em: 18/12/2009.

ARRUTI, José Maurício Andion. Morte e vida do Nordeste indígena: a emergência étnica como fenômeno histórico regional. Estudos Históricos, v.8, n.15, p. 55-94, 1995. 
CAUME, David J. A história de uma escola para índios: Colégio Isabel (Goiás, 18701888). Inter-Ação, Goiás, v. 21, n.1-2, p.97-124, jan./dez.1997.

CHARTIER, Roger. A História Cultural: entre práticas e representações. Rio de Janeiro: Bertrand Brasil, 1990.

CUNHA, Manoel Clementino Carneiro da. Falla com que o exm. sr. doutor Manoel Clementino Carneiro da Cunha abrio a sessão da Assembléa Legislativa Provincial de Pernambuco em 2 de março de 1877. Pernambuco, Typ. de M. Figueirôa de Faria \& Filhos, 1877. Disponível em: 〈http://brazil.crl.edu/bsd/bsd/692/000079.html >. Acesso em: $18 / 12 / 2009$.

CUNHA, Manuela Carneiro da (Org.). Legislação indigenista no século XIX. São Paulo: EDUSP, Comissão Pró-Índio de São Paulo, 1992.

. Política indigenista no século XIX. In: História dos índios no Brasil. São Paulo: Companhia das Letras: Secretaria Municipal de Cultura: FAPESP, 1998.

FARIA FILHO, Luciano Mendes de, GONCALVES, Irlen Antônio, VIDAL, Diana Gonçalves, PAULILO, André Luiz. A cultura escolar como categoria de análise e como campo de investigação na história da educação brasileira. Educação e Pesquisa, vol. 30, $\mathrm{n}^{\circ}$. 1, p. 139-159, jan./abr. 2004. Disponível em: 〈http://www.scielo.br〉. Acesso em: $31 / 05 / 2010$.

FONSECA, Marcus Vinicius. A Educação dos negros: uma nova face do processo de abolição do trabalho escravo. Bragança Paulista: Editora da Universidade São Francisco, 2002.

GASPAR, Lúcia. Índios Xucuru. Recife: Fundação Joaquim Nabuco, 2009. Disponível em: 〈http://www.fundaj.gov.br >. Acesso em: 21/12/2009.

GOMES, Mércio Pereira. $O$ índio na história: o povo Tenetehara em busca da liberdade. Petrópolis: Vozes, 2002.

GONÇALVES, Domingos Maria. Collegio dos indios de Urubá de agricultura, e artes industriaes. Recife: Typ. Universal, 1874.

A instrucção agricola e o trabalho livre. Rio de Janeiro: Typ. Central, 1880. (Precedido de uma carta ao Exmo Dr. Joaquim Nabuco, deputado geral).

GONÇALVES, Domingos Maria. Esboço biographico do Comendador Raphael Ascoly, natural de Lisboa. Rio de Janeiro: Typ. Central de Evaristo Rodrigues da Costa, 1880b.

. Exposição ao Poder Legislativo (sobre ensino profissional agrícola). Rio de Janeiro: Typ. Nacional, 1882.

LUCENA, Henrique Pereira de. Falla com que o excellentissimo senhor desembargador Henrique Pereira de Lucena abrio a Assemblêa Legislativa Provincial de Pernambuco em 
$o 1^{o}$ de março de 1875. Pernambuco, Typ. de M. Figueiroa e F. \& Filhos, 1875. Disponível em: 〈http://brazil.crl.edu/bsd/bsd/690/000146.html〉. Acesso em: 18/12/2009.

MAGALHÃES, José Vieira Couto de. O selvagem. Belo Horizonte: Itatiaia, São Paulo: EDUSP, 1975 [1875].

Região e raças selvagens. Rio de Janeiro: Revista do Instituto Histórico e Geográfico Brasileiro, 36, 1-2, p. 359-516, 1873.

MOREIRA NETO, Carlos de. A política indigenista brasileira durante o século XIX. Tese (Doutorado em Antropologia). Rio Claro, SP: Faculdade de Filosofia, Ciências e Letras de Rio Claro, 1971.

OLIVEIRA, João Pacheco. Uma etnologia dos “índios misturados"? Situação colonial, territorialização e fluxos culturais. In: A viagem da volta: etnicidade, política e reelaboração cultural no Nordeste indígena. Rio de Janeiro: Contra Capa, 1999.

RIZZINI, Irma; MENESES, Kesley. Historia das minhas tentativas para o estabelecimento d'escolas agricolas: os projetos do cônsul Domingos Maria Gonçalves para a formação do trabalhador livre. Anais do I Encontro de História da Educação do Estado do Rio de Janeiro (I EHEd-RJ). Niterói: Universidade Federal Fluminense, 2007.

; SCHUELER, Alessandra Frota Martinez de. Índios e missionários no ensino e na História da Educação: o caso do Instituto do Prata (Pará, 1898-1913). Anais do IX Congresso Iberamericano de História da Educação na América Latina. Rio de Janeiro: UERJ, 2009.

SCHUELER, Alessandra Frota Martinez de. A "infância desamparada" no asilo agrícola de Santa Isabel: instrução rural e infantil (1880 - 1886). Educ. Pesqui., São Paulo, v. 26, n. 1, 2000. Disponível em: 〈http://www.scielo.br〉. Acesso em 22/12/2009.

SCHWARCZ, Lilia Moritz. Nomeando as diferenças: a construção da idéia de raça no Brasil. In: BÔAS, Glaucia Villas, GONÇALVES, Marco Antônio. O Brasil na virada do século: o debate dos cientistas sociais. Rio de Janeiro: Relume Dumará, 1995a. 177-191

O espetáculo das raças: cientistas, instituições e questões raciais no Brasil (18701930). São Paulo: Cia das Letras, 1995 b.

SILVA, Edson Hely. O lugar do índio. Conflitos, esbulhos de terras e resistência indígena no século XIX: o caso de Escada-PE (18601880). Dissertação (mestrado em História). Recife: Universidade Federal de Pernambuco, 1995.

SILVA, Edson. História, memórias e identidade entre os Xukuru do Ororubá. Tellus, ano 7, n.12, abr. 2007. Disponível em: 〈ftp://neppi.ucdb.br/pub/tellus/tellus12/5_Edson.pdf>. Acesso em: 22/12/2009.

SILVA, Innocencio da. Diccionario bibliographico dos escriptores portuguezes. Lisboa: Imprensa Nacional, v. IX, 1858-1923. 
SOUZA, João Cardoso de Menezes e (Conselheiro; Barão de Paranapiacaba). Theses sobre colonização do Brazil: projecto de solução ás questões sociaes, que se prendem a este difficil problema. Relatorio apresentado ao Ministerio da Agricultura, Commercio e Obras Publicas em 1875. Rio de Janeiro: Typ. Nacional, 1875.

SOUZA, Maria Zélia Maia de. Educar, trabalhar e civilizar no Asilo de Meninos Desvalidos (1875-1894): caminhos possíveis. Dissertação (Mestrado em Educação). Rio de Janeiro: Universidade Federal do Estado do Rio de Janeiro (UNIRIO), 2008.

SOUZA FILHO, Tarquinio de. O ensino technico no Brasil. Rio de Janeiro: Imprensa Nacional, 1887. (Livros de Propaganda da Sociedade Central de Immigraçao, III)

\footnotetext{
${ }^{1}$ Professora de História da Educação do Curso de Pedagogia e do Programa de Pós-Graduação em Educação da UFRJ. Pesquisadora do Programa de Estudos e Documentação Educação e Sociedade (PROEDES/FE/UFRJ). O trabalho é resultado do projeto de pesquisa "A educação das infâncias: internatos públicos e religiosos de ensino profissional (1870-1910)", apoiado pela FAPERJ, e foi apresentado no VII Congresso Luso-Brasileiro de História da Educação, na Universidade do Porto, em 2008.

${ }^{2}$ A lei n ${ }^{\circ} 2040$, de 28 de setembro de 1871, entre outras medidas, tornou livre os filhos das escravas nascidos após esta data. A lei impunha condições a essa liberdade, conforme está estabelecido no artigo $1^{\circ}, \S 1^{\circ}$.

${ }^{3} \mathrm{O}$ aldeamento, cujo nome oficial era Cimbres, se localizava na Serra do Ororubá (denominada Serra do Urubá, na obra de Gonçalves e nos relatórios provinciais), a $200 \mathrm{~km}$ de Recife em linha reta. Disponível em: <http://www.mj.gov.br/data/Pages/MJA63EBC0EITEMIDA1FD45A30C6F47E0B8DC7B2D37BECB1BPT BRIE.htm>. Acesso: em 18/12/2009.

${ }^{4}$ A respeito, ver Direcção dos Consulados e dos Negócios Comerciais, em 23 de Setembro de 1870, disponível em: <www.ics.ul.pt/ahsocial/list_mfm/06.pdf>. Acesso em: 18/12/2009.

${ }^{5}$ Fonseca (2002) esclarece que ingênuo era a denominação usual no plano social, conferida às crianças nascidas livres de mães escravas, após a lei de 1871. O termo é uma herança do direito romano e designava os filhos de pais libertos.

${ }^{6}$ A respeito dos projetos educacionais de Domingos Maria Gonçalves, dirigidos aos filhos das escravas, ver Rizzini e Meneses, 2007.

${ }^{7}$ Com base no conceito operado por Chartier (1990), as representações são aqui compreendidas como práticas sociais, capazes de intervir na vida social e produzir novas práticas. As representações são construções históricas, vinculadas aos interesses de determinados grupos sociais em impor aos demais grupos seus valores e visões de mundo.

${ }^{8}$ A principal lei indigenista do Império, o "Regulamento acerca das Missões de catechese e civilização dos Indios" (Dec. n.426 de 21/07/1845), prolongou a política colonial de criação de aldeamentos controlados pelo poder público, introduzida em 1757, com o Diretório dos Índios. Os aldeamentos reuniam índios de etnias diferentes, submetidos ao "jugo das leis" e à ação civilizadora e catequética dos missionários. Com a sedentarização dos grupos indígenas, territórios e mão-de-obra tornavam-se disponíveis para a colonização dos sertões. A respeito da política indigenista do século XIX, ver os trabalhos de Manuela Cunha (1992, 1998).

${ }^{9}$ Segundo o levantamento realizado, em 1857, pela Comissão de Demarcação das Terras Públicas da Capitania de Pernambuco, o aldeamento de Cimbres (Urubá, na obra de Gonçalves) estava localizado a 64 léguas de Recife, ocupando uma área sem medição oficial, com cerca de três por duas léguas. Cimbres era o mais povoado dos oito aldeamentos existentes na Província em 1857, possuindo 789 habitantes, distribuídos em 238 famílias (ARRUTI, 1995, p. 67). Informações sobre o aldeamento e a situação atual dos remanescentes Xukuru estão disponíveis em:

<http://www.mj.gov.br/data/Pages/MJA63EBC0EITEMIDA1FD45A30C6F47E0B8DC7B2D37BECB1BPT BRIE.htm> Acesso em: 18/12/2009.

${ }^{10} \mathrm{Na}$ segunda metade do século XIX, autores poligenistas, isto é, que defendiam a origem diversificada das raças humanas, acreditavam que o mestiço herdaria somente as características "ruins" de cada uma das raças constituintes, levando o gênero humano à degeneração (SCHWARCZ, 1995b).

${ }^{11}$ Deve ser esclarecido aqui que Gonçalves teve contato com índios aldeados pela Diretoria de Índios de Pernambuco, portanto ele está se referindo a uma realidade específica dos índios das províncias do litoral norte do século XIX.
} 
${ }^{12}$ Comte de Hure, L’Empire du Brésil"; Saint-Hilaire, Voyage au Brésil; Horace Say, Historie des Relations Commerciales entre la France et le Brésil; J. I. de Abreu e Lima, Historia do Brazil.

${ }^{13} \mathrm{O}$ autor parece compartilhar com Couto de Magalhães a visão da degeneração do índio aldeado. "Cada tribo que aldeamos é uma tribo que degradamos" afirmava Magalhães, em artigo à Revista do Instituto Histórico e Geográfico Brasileiro (1873, p. 511).

14 "Escriptura publica do contracto que fazem o Exmo. Barão de Buique e o Dr.Domingos Maria Gonçalves". Contrato selado no cartório da vila de Pesqueira, termo da comarca de Cimbres, em 12/03/1874. O contrato foi publicado na íntegra por Domingos Gonçalves $(1874 ; 1880)$ e reproduzido no relatório do Conselheiro Menezes e Souza, encarregado pelo Ministro da Agricultura de apresentar soluções para a colonização do país. Souza (1875) dedicou quase 100 páginas do seu extenso relatório à educação dos futuros colonos do país: as crianças pobres, desvalidas, abandonadas, indígenas e nascidas livres.

${ }^{15} \mathrm{O}_{\text {decreto }} \mathrm{n}^{\mathrm{o}} 1.318$, de $30 / 11 / 1854$, que regulamentou a Lei das Terras, previa a garantia da propriedade da terra por índios considerados em "estado de civilização", disposição burlada por municípios, províncias e Império (CUNHA, 1998, p. 145-146). Na prática, a aquisição da cidadania brasileira pelos índios da aldeia de Urubá aceleraria o processo de extinção do aldeamento.

16 A Constituição do Império (1824) não menciona índios, apesar do projeto de José Bonifácio, Apontamentos para a civilisação dos Indios bravos do Imperio do Brazil, ter recebido parecer favorável da Assembléia Constituinte do Brasil independente (CUNHA, 1998, p. 138).

${ }^{17}$ Sobre os conflitos em torno das terras e a resistência indígena em Pernambuco nas décadas de 1860 a 1880 , ver o trabalho de Edson Silva (1995).

${ }^{18}$ O levantamento de 1857, realizado junto aos oito aldeamentos de Pernambuco, cita ocorrências de expropriações de terras, por meios violentos ou legais. Até o final da década de 1870 fecha-se o "círculo do processo de conquista", com a extinção dos aldeamentos da região. O século seguinte assistirá à emergência étnica de vários grupos indígenas remanescentes do Nordeste (ARRUTI, 1995).

1919 Em 1875, o governo pernambucano instalou a Colônia Orfanológica Isabel, sob a administração de missionários capuchinhos. A Colônia oferecia o ensino de ofícios e agrícola a meninos pobres, instalada em vasta área da extinta colônia militar de Pimenteiras Os relatórios provinciais das décadas de 1870 e 1880 reservam um significado espaço para as informações sobre a Colônia e para os relatórios do diretor frei Fognano, ao contrário do que ocorre com os aldeamentos indígenas.

20 A expressão "índios misturados" aparece freqüentemente nos relatórios provinciais do Norte (atual Nordeste), quando os índios da região deixam de ser vistos por sua especificidade étnica, por se encontrarem vivendo miscigenados à população não índia, em termos econômicos, culturais e raciais. A chamada "mistura" não ocorreu como um processo natural de integração de populações que mantinham intercâmbios diversos; antes resultou da política de assimilação implementada pelo Governo Imperial, através dos aldeamentos (OLIVEIRA, 1999).

${ }^{21}$ Governo Provisorio da Republica dos Estados Unidos do Brasil. Decreto $\mathrm{n}^{\mathrm{o}}$ 119-A, de 7 de janeiro de 1890. Prohibe a intervenção da autoridade federal e dos Estados federados em materia religiosa, consagra a plena liberdade de cultos, extingue o padroado e estabelece outras providencias.

${ }^{22}$ João Pacheco de Oliveira (1999) analisa a construção, nas últimas décadas do século XX, do objeto "índios do Nordeste", processo impulsionado pelo ressurgimento de etnias tidas como extintas, e suas implicações para a etnologia e para a política indigenista.

${ }^{23}$ O depoimento do cacique Francisco Assis Araújo, líder do povo Xukuru do Ororubá, assassinado em 1998, demonstra que o esforço de resgate cultural, através da educação escolar diferenciada das novas gerações e da realização de festas e rituais da tradição da etnia, é uma das estratégias empregadas na luta pela homologação das terras indígenas, processo ocorrido há pouco mais de quatro anos. Ver em: <http://video.google.com/videoplay?docid=-8537518505098293066\#>. Acesso em: 22/12/2009.

Artigo recebido em: 29/01/2010

Aprovado para publicação em: 18/03/2010 